\section{International Scientific Journal Theoretical \& Applied Science}

\author{
p-ISSN: 2308-4944 (print) e-ISSN: 2409-0085 (online) \\ Year: $2016 \quad$ Issue: $1 \quad$ Volume: 33 \\ Published: $30.01 .2016 \quad$ http://T-Science.org
}

SECTION 7. Mechanics and machine construction.
Kirill Olegovich Semenov

Undergraduate of the Department «Equipment and technology of machine-building production» FSBEI HPE «Togliatti State University», Russia semen-tgu@yandex.ru

Danila Vasilyevich Nazarov Undergraduate of the Department «Equipment and technology of machine-building production» FSBEI HPE «Togliatti State University», Russia danila.nazarov92@yandex.ru

\title{
MODERN TRENDS IN THE DEVELOPMENT OF TECHNOLOGIES OF HARDENING CUTTING TOOL FROM HIGH-SPEED STEEL
}

\author{
Abstract: The article considers the main methods of applying high performance protective coatings (ion - \\ plasma treatment and electrospark alloying) on the surface of the cutting tool to its strengthening and improving \\ operational characteristics. Presents research on durability of the tool. \\ Key words: Cutting tool, high-speed steel, hardening, ion-plasma treatment, electrospark alloying. \\ Language: Russian \\ Citation: Semenov KO, Nazarov DV (2016) MODERN TRENDS IN THE DEVELOPMENT OF \\ TECHNOLOGIES OF HARDENING CUTTING TOOL FROM HIGH-SPEED STEEL. ISJ Theoretical \& \\ Applied Science, 01 (33): 101-105. \\ Soi: http://s-o-i.org/1.1/TAS-01-33-18 Doi: crossef http://dx.doi.org/10.15863/TAS.2016.01.33.18

\section{СОВРЕМЕННЫЕ ТЕНДЕНЦИИ В РАЗВИТИИ ТЕХНОЛОГИЙ УПРОЧНЕНИЯ РЕЖУЩЕГО ИНСТРУМЕНТА ИЗ БЫСТРОРЕЖУЩЕЙ СТАЛИ}

Аннотация: B статье рассматриваются основные высокоэффективные методы нанесения защитных покрытий (ионно-плазменная обработка и электроискровое легирование) на поверхность режущего инструмента для его упрочнения и повышения эксплуатациионных показателей. Представлены исследования по стойкости инструмента.

Ключевые слова: Режущий инструмент, быстрорежущая сталь, упрочнение, ионно-плазменная обработка, электроискровое легирование.

\section{Введение}

В современных технологиях обработки металлов резанием применение режущих инструментов из быстрорежущей стали составляет $45 \%$, поэтому развитие машиностроительных, инструментальных и других отраслей промышленности предопределило значительный рост интенсификации режимов резания и вызывает как следствие, повышенный расход режущего инструмента [5].

Одним из эффективных средств сокращения расхода инструмента при высоком уровне производительности металлообработки является применение инструмента $\mathrm{c}$ износостойкими покрытиями.

Износостойкие покрытия позволяют получить рабочие поверхности инструмента с необходимыми служебными характеристиками, как правило, не изменяя свойств основного инструмента. Поэтому особенно актуальными становятся задачи по упрочнению и продлению срока службы режущего инструмента.

Среди многообразия способов по упрочнению режущего инструмента из быстрорежущей стали, при помощи нанесения на его поверхность защитных покрытий заметно выделяются методы: ионно-плазменная обработка и электроискровое легирование, отличающиеся простотой исполнения, технической и экономической целесообразностью, а также экологической чистотой $[3,7]$.

В настоящее время ионно-плазменная обработка и электроискровое легирование зарекомендовали себя как эффективные методы по нанесению защитных покрытий на режущий инструмент. Однако электроискровое легирование всё реже используется на производстве, в отличие от ионно-плазменной обработки это связано с его низкой производительностью и преимущественно с 


\begin{tabular}{|c|c|c|c|c|c|c|}
\hline Impact Factor: & $\begin{array}{l}\text { ISRA (India) } \\
\text { ISI (Dubai, UAB } \\
\text { GIF (Australia) } \\
\text { JIF }\end{array}$ & $\begin{array}{r}=1.344 \\
=0.829 \\
=0.564 \\
=1.500\end{array}$ & $\begin{array}{l}\text { SIS (USA) } \\
\text { PИHЦ (Russia) } \\
\text { ESJI (KZ) } \\
\text { SJIF (Morocco) }\end{array}$ & $\begin{array}{l}=0.912 \\
=0.179 \\
=1.042 \\
=2.031\end{array}$ & $\begin{array}{l}\text { ICV (Poland) } \\
\text { PIF (India) }\end{array}$ & $\begin{array}{l}=6.630 \\
=1.940\end{array}$ \\
\hline
\end{tabular}

ручным применением. Но недостатки этого метода, не мешают ему оставаться на производстве и применяться на ряду как с ионноплазменной обработкой, так и с другими методами.

При использовании этих методов для упрочнения режущего инструмента, как для быстрорежущей стали, так и для любых других деталей и сплавов основополагающими факторами, является корректная оценка режущего инструмента по износостойкости, выносливости, прочности, а также качества и свойств получаемого покрытия.

\section{Ионно-плазменная обработка}

Ионно-плазменная обработка применяется для повышения износостойкости и коррозионной стойкости режущих инструментов, коленчатых валов, деталей насосов, дизелей и других деталей, подвергающихся изнашиванию и коррозионному воздействию.

Покрытие получают способами термического испарения, катодного или ионноплазменного распыления, либо путём

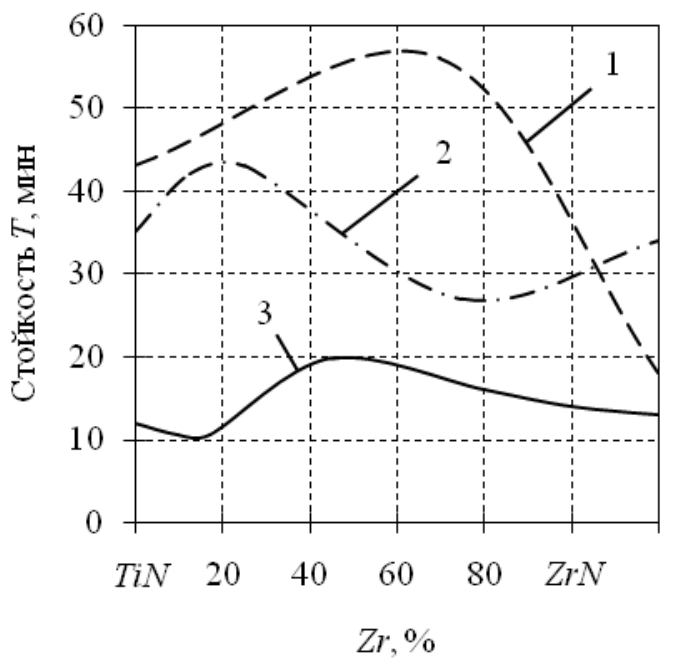

- - - Сталь $40 \mathrm{X} \quad-\cdot-$ Сталь $12 \mathrm{X} 18 \mathrm{H} 10 \mathrm{~T}$

Рисунок 1 - Влияние состава покрытия $(\mathrm{Ti}, \mathrm{Zr}) \mathrm{N},(\mathrm{Ti}, \mathrm{Mo}) \mathrm{N}$ на период стойкости пластин из быстрорежущей стали Р6М5 при обработке заготовок с режимами резания: $S=0,3$ мм/об; $t=1,0$ мм; $1-V=75$ м/мин; $2-V=10$ м/мин; $3-V=28$ м/мин
Применение износостойких покрытий существенно повышает период стойкости пластин из быстрорежущей стали при обработке тех или иных заготовок примерно в 1,3 раза.

\section{Электроискровое нанесение покрытий}

Низковольтные электрические разряды позволяют модифицировать состав и структуру поверхностных слоев быстрорежущих сталей за счет термомеханического воздействия электрических разрядов и переноса вещества с бомбардировки поверхности ионами осаждаемого вещества. В качестве реакционного газа используют азот или углерод $[4,10]$.

Общие преимущества от других методов нанесения покрытий:

- более высокая прочность сцепления и плотность полученных покрытий из-за высокой энергии распыленных частиц;

- возможность получения покрытий из особо тугоплавких и неплавящихся материалов;

- возможность получения супертвердых или нанокомпозитных покрытий;

- возможность управления составом и свойствами покрытия в процессе нанесения;

- повышение износостойкости и коррозионной стойкости.

Недостатки метода:

- небольшое количество загрязнений в материале покрытий; изделия.

- объем камеры ограничивает размер

С помощью этого метода проведем исследование двухэлементных нитридных покрытий $(T i, Z r) N$ и $(T i, M o) N,($ рисунок 1).

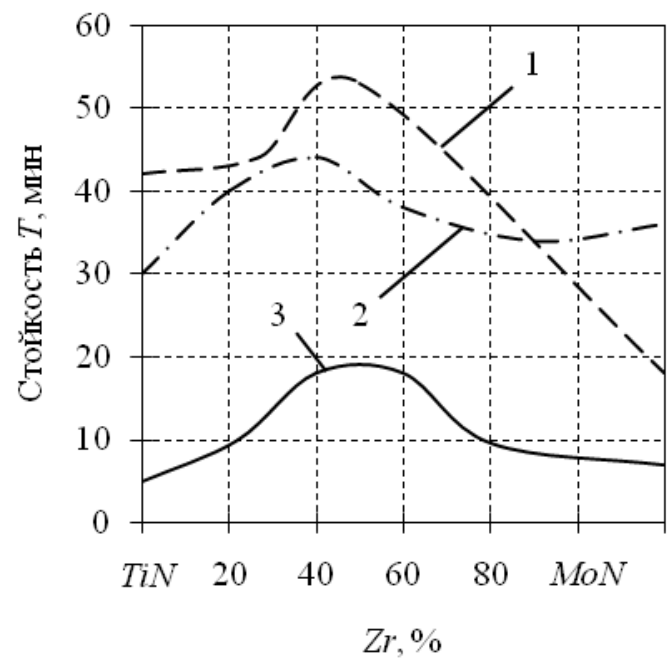

- Титановый сплав ВТ22 одного электрода на другой. В результате на быстрорежущей стали формируется покрытие в виде сплава обоих электродов, а также продуктов их взаимодействия с элементами межэлектродной среды [1].

Рассмотрим процесс ЛЭНП на примере установки Эльфа-541, (рисунок 2).

Процесс начинается со сближения анода (электрода) с катодом (деталью). При расстоянии между ними равном пробивному начинается развитие искрового разряда длительностью $10^{-6}-$ 


\begin{tabular}{l|lrl|l|ll} 
& ISRA (India) & $=\mathbf{1 . 3 4 4}$ & SIS (USA) & $=\mathbf{0 . 9 1 2}$ & ICV (Poland) & $=\mathbf{6 . 6 3 0}$ \\
Impact Factor: & ISI (Dubai, UAE) $=\mathbf{0 . 8 2 9}$ & PUHL (Russia) $=\mathbf{0 . 1 7 9}$ & PIF (India) & $=\mathbf{1 . 9 4 0}$ \\
& GIF (Australia) & $\mathbf{0 . 5 6 4}$ & ESJI (KZ) & $=1.042$ & & \\
& JIF & $\mathbf{1 . 5 0 0}$ & SJIF (Morocco) $=\mathbf{2 . 0 3 1}$ & &
\end{tabular}

$10^{-3} \mathrm{c}$, который во многих случаях завершается при контакте электродов.

Преимущественный перенос эродируемого материала анода на катод обеспечивает формирование на нем измененного поверхностного слоя. Образуется на поверхности изделия измененный слой, включающий белый слой, диффузионную зону и зону термического влияния; формируется поверхностный слой мелкодисперсного состава, вплоть до наноуровня; происходит изменение размера изделия.

После окончания импульсного искрового разряда и отхода анода от катода завершается разрыв электрической цепи. Реализация непрерывного процесса электроискрового нанесения покрытий за счет периодической коммутации анода с катодом осуществляется с помощью специальных устройств, например, вибратора с закрепленным на нем анодом [2].

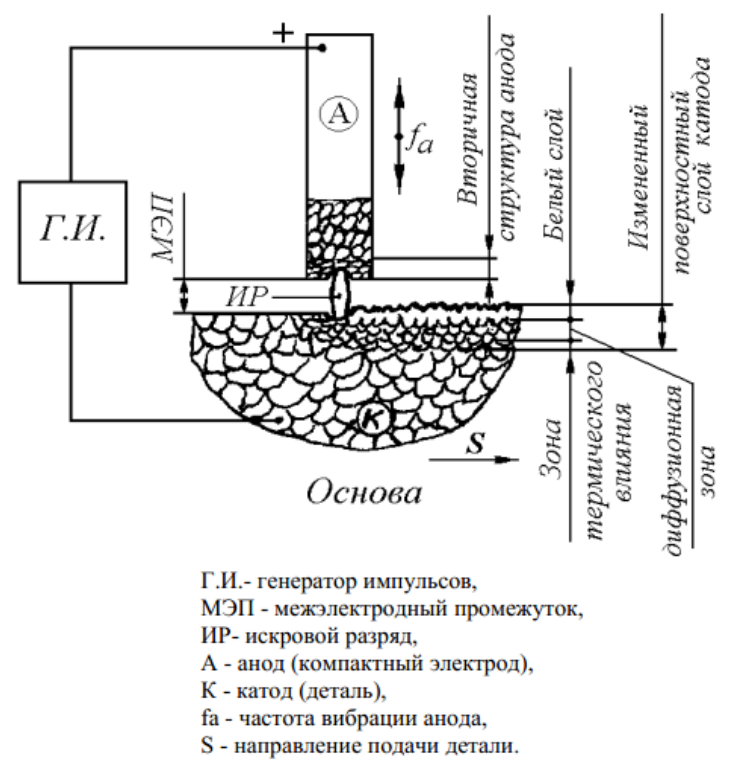

Рисунок 2 - Общая схема электроискрового нанесения покрытий

Преимущества ЭИЛ:

- высокий коэффициент переноса материала $(60-80 \%)$

- низкая энергоемкость ручных и механизированных процессов (0,5-2,0 кВт);

- простота обслуживания и надежность оборудования, которое малогабаритно и транспортабельно;

- высокая адгезия с основным материалом;

- отсутствие нагрева и деформаций изделия в процессе обработки;

- сравнительная простота технологии, которая не требует специальной предварительной обработки поверхности.

Недостатки:

- высокая шероховатость поверхности

Ra 3,2-6,3;
- низкая производительность;

- преимущественно ручной труд.

Испытания на износостойкость проведены на инструментах из быстрорежущей стали Р6М5: a - автоматный резец; б - сверло спиральное Ø14; в - метчик М16х2; г - резцы зуборезные; д фреза концевая Ø50.

Использовалось износостойкое покрытие из $T i N$ нитрида титана. Все испытания проводились при разных оптимальных скоростях резания: $V=30$ м/мин; $V=15$ м/мин; $V=6$ м/мин; $V=35$ м/мин; $V=32$ м/мин. В качестве обрабатываемого материала служили стали: 40Х, 08X17Т, 12ХНЗА, $45[8,9]$.

По проведенным исследованиям получили результаты, (рисунок 3). 


\begin{tabular}{l|lrl|l|ll} 
& ISRA (India) & $=\mathbf{1 . 3 4 4}$ & SIS (USA) & $=\mathbf{0 . 9 1 2}$ & ICV (Poland) & $=\mathbf{6 . 6 3 0}$ \\
Impact Factor: & ISI (Dubai, UAE) $=\mathbf{0 . 8 2 9}$ & PUHU (Russia) $=\mathbf{0 . 1 7 9}$ & PIF (India) & $=\mathbf{1 . 9 4 0}$ \\
& GIF (Australia) & $\mathbf{0 . 5 6 4}$ & ESJI (KZ) & $=\mathbf{1 . 0 4 2}$ & & \\
& JIF & $=\mathbf{1 . 5 0 0}$ & SJIF (Morocco) $=\mathbf{2 . 0 3 1}$ & &
\end{tabular}

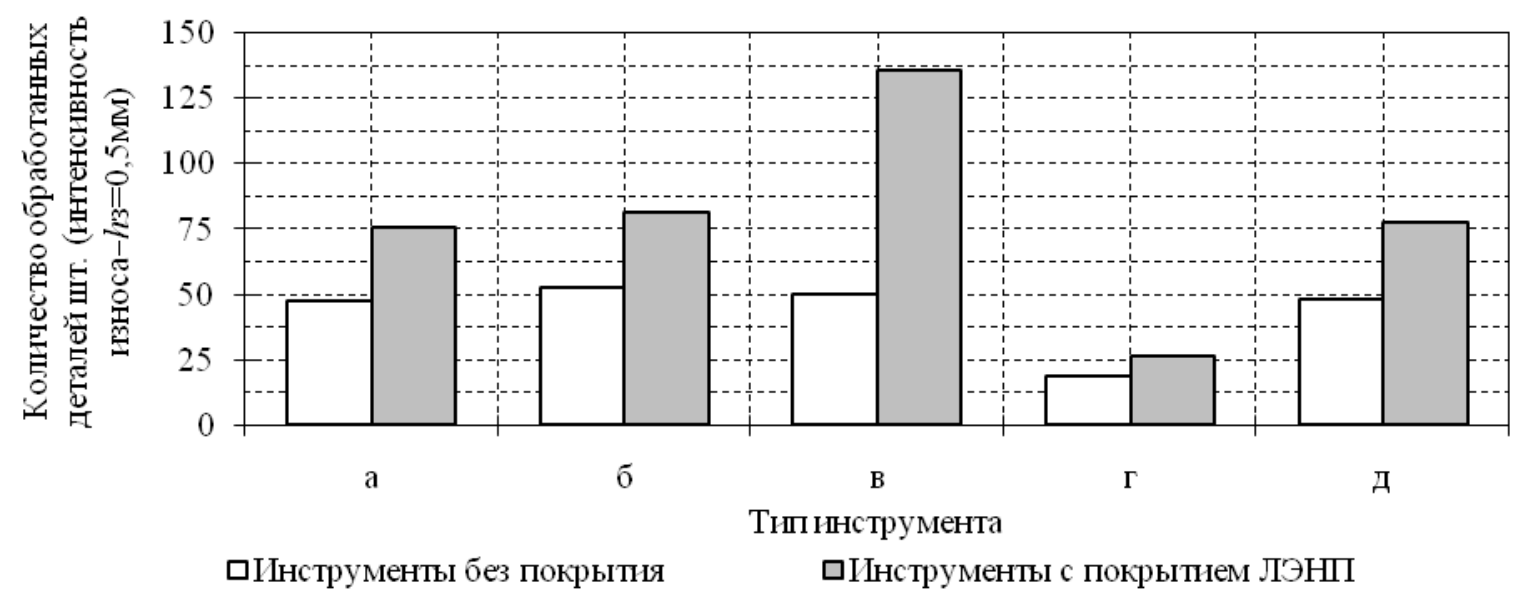

Рисунок 3 - Результаты стойкостных испытаний инструментов из быстрорежущей стали Р6М5

По полученным результатам можно сказать, что стойкость режущего инструмента после упрочнения ЭИЛ увеличивается в несколько раз: зуборезных резцов от 1,21 до 1,93 ; метчиков от 2,24 до 2,74; сверл от 1,2 до 1,54 и концевых фрез до 1,7 раза.

\section{Обработка и анализ результатов}

Эффективность покрытий повышается при резании на высоких скоростях, однако она может снижаться ввиду склонности быстрорежущей стали к пластическому разрушению (что заметно при высоких скоростях резания).

Покрытие принципиально не меняет характер зависимости стойкости от режимов резания, однако интенсивность снижения стойкости у инструмента с покрытием значительно ниже, что делает применение инструмента с покрытием целесообразным на высоких скоростях резания при относительно небольших подачах.

Износостойкость режущего инструмента оказалась выше при ионно-плазменной обработке. Кроме того, метод обладает большей склонностью к автоматизации, тогда как ЭИЛ происходит практически вручную, что сильно увеличивает время нанесения покрытия, а следовательно и стоимость этого метода $[5,6]$.

Эффективность метода ионно-плазменной обработки очевидна при массовом производстве инструмента. Покрытие наносится на всю поверхность инструмента, а износу подвергаются только поверхности в близи режущей кромки. С этой точки зрения весьма предпочтительней выглядит процесс ЭИЛ.

Рассмотрены и проанализированы все достоинства и недостатки этих методов и отталкиваясь от того, что методом электроискрового легирования позволяет наносить покрытия не только на всю поверхность режущего инструмента, а отдельно только на те поверхности, которые подвергаются износу в близи режущей кромки.

Поэтому с этой точки зрения весьма предпочтительней выглядит процесс ЭИЛ.

Исследование выполнено под руководством Логинова Н.Ю., к.т.н, доиент кафедры «Оборудование и технологии машиностроительного производства» ФГБОУ ВПО «Тольяттинский государственньй университет», Россия.

\section{References:}

1. Gadalov VN, Abashkin RE, Boldyrev Yu.V, Balabaeva EF, Lytkin AI (2009) Research tool wear and hardening of high speed steels by local electric-coating // "STIN". 2009. №1. pp. 20-25.

2. Ippolitov VN (2007) Increased cutting properties of high speed steel tools based on the modification of their working surfaces by spraying of an electro-doping // Abstract of dissertation for the degree of candidate of technical sciences, $2007-18 \mathrm{p}$.

3. Kishurov VM, Ippolitov VN, Kishurov MV, Nekrasova MY (2011) The wear resistance of 


\begin{tabular}{|c|c|c|c|c|c|c|}
\hline Impact Factor: & $\begin{array}{l}\text { ISRA (India) } \\
\text { ISI (Dubai, UAF } \\
\text { GIF (Australia) } \\
\text { JIF }\end{array}$ & $\begin{array}{l}=1.344 \\
=0.829 \\
=0.564 \\
=1.500\end{array}$ & $\begin{array}{l}\text { SIS (USA) } \\
\text { PИНЦ (Russia) } \\
\text { ESJI (KZ) } \\
\text { SJIF (Morocco }\end{array}$ & $\begin{aligned}=0.912 \\
=0.179 \\
=1.042 \\
=\mathbf{2 . 0 3 1}\end{aligned}$ & $\begin{array}{l}\text { ICV (Poland) } \\
\text { PIF (India) }\end{array}$ & $\begin{array}{l}=6.630 \\
=1.940\end{array}$ \\
\hline
\end{tabular}

the cutting tools of high speed steel coated // "STIN". 2011. №10. pp. 23-27.

4. Komova EA, Rodichkin AV (2011) Methods hardening ion-plasma treatment // Murom Institute of Vladimir State University named after Alexander G. and Nicholas G. Stoletovs. $2011-175 \mathrm{p}$.

5. Loginov NY (2005) The increase cutting tool life by electric spark: the dissertation for the degree of candidate of technical sciences: 05.02.08. Togliatti, 2005. - $140 \mathrm{p}$.

6. Loginov NY, Loginov YN (2005) Hardening of tool by electric-doping // News TSU. Ser. Instrumentation and metrology systems. Issue 1. Proceedings of the International jubilee scientific conference "Science of cutting materials in modern conditions", dedicated to the 90th anniversary of VF Bobrov, 9-11 February 2005 Part 1: Tula: Tula State University, 2005. - pp. 93-96.

7. Makarov AD (1966) Wear resistance and cutting tools. Moscow: Mechanical engineering. - $1966-264 \mathrm{p}$.

8. Romanenko EF (2011) Examination of coatings on high speed steel produced by local electriccoating. // "Reinforcing and coating technology." 2011. №5. pp. 38-43.

9. Samsonov GV, Verkhoturov AD, Bovkun GA, Sychev VS (1976) Electric spark alloying metal surfaces. Kiev, Naukova Dumka, 1976. - 220 p.

10. Tabakov VP (2008) Formation of wear-resistant ion-plasma coating of the cutting tool. Moscow: Engineering, 2008. - 315 p. 